\title{
DIGESTÃO ANAERÓBIA DE RESÍDUOS ALIMENTARES UTILIZANDO ENSAIOS BMP
}

\author{
ANAEROBIC DIGESTION OF THE FOOD WASTE USING BMP ASSAY \\ Matheus Vitor Diniz Gueri ${ }^{1}$, Samuel Nelson Melegari de Souza ${ }^{2}$, Osvaldo Kuczman ${ }^{3}$, Waldir \\ Nagel Schirmer ${ }^{4}$, William Gouvêa Buratto ${ }^{5}$, Camilo Bastos Ribeiro ${ }^{6}$, Geovanny Broetto Besinella ${ }^{7}$ \\ 1,2,3 Universidade Estadual do Oeste do Paraná, Cascavel, Paraná, Brasil-mgueri@hotmail.com, \\ samuel.souza@unioeste.br \& osvaldokuczman@hotmail.com \\ 4, 6 Universidade Estadual do Centro Oeste, Irati, Paraná, Brasil-wanasch@hotmail.com \& \\ cb_ambiental@hotmail.com \\ ${ }^{5}$ Instituto Federal de Santa Catarina, Florianópolis, Santa Catarina, Brasil - williamburatto@gmail.com \\ ${ }^{7}$ Universidade Federal do Paraná, Palotina, Paraná, Brasil-engamb.geo@hotmail.com
}

\section{RESUMO}

A preocupação com a preservação do meio ambiente e a necessidade de diversificação da matriz energética são alguns dos fatores que têm impulsionado a busca por energias alternativas. Nesse contexto, o presente trabalho analisou o processo de digestão anaeróbia de resíduos alimentares provenientes de um restaurante popular, observando o potencial bioquímico da geração de metano. 0 experimento consistiu no uso de reatores anaeróbios em regime batelada com volume de $250 \mathrm{~mL}$, sendo $150 \mathrm{~mL}$ de volume útil à geração de biogás (headspace) e $100 \mathrm{~mL}$ remanescente preenchido nas proporções de 1:1 de substrato:inoculo, em relação ao teor de sólidos voláteis (gSV inoculo: $\left.\mathrm{gSV}_{\text {substrato }}\right)$. Os reatores foram operados por 30 dias sob temperatura constante em $30^{\circ} \mathrm{C}$. Os resultados obtidos apresentam o teor de sólidos voláteis dos resíduos alimentares de $85,21 \%$ e uma relação C/N de 18,81 . Foi possível alcançar uma produção específica de metano de $0,311 \mathrm{Nm}^{3} \cdot \mathrm{kgSVr}^{-1}$ e reduções de $23,58 \%$ para SV e de $81,27 \%$ para DQO.

PALAVRAS-CHAVE: Biogás, Energias Renováveis, Potencial Bioquímico de Metano, Resíduos Alimentares.

\begin{abstract}
The concern with the preservation of the environment and the need to diversify the energy matrix are some of the factors that have driven the search for alternative energies. In this context, the present research aimed to perform anaerobic digestion of food wastes from a popular restaurant, verifying the biochemical methane potential (BMP). The experiment consisted in using anaerobic reactors of $250 \mathrm{~mL}$ operated under batch conditions, using $150 \mathrm{~mL}$ as useful volume to biogas generation (headspace) and the remaining volume was filled in the proportion 1:1 substrate:inoculum, in relation to the volatile solids content $\left(\mathrm{VS}_{\text {substrate }}: \mathrm{VS}_{\text {inoculum }}\right)$. The reactors were operated for 30 days under constant temperature at $30^{\circ} \mathrm{C}$. The results obtained shown the volatile solids (VS) content of food wastes of $85.21 \%$ and a $\mathrm{C} / \mathrm{N}$ ratio of 18.81 . It was possible to achieve a specific production of methane of $0.311 \mathrm{Nm}^{3} . \mathrm{kgVSr}^{-1}$ and reductions of $23.58 \%$ for VS and of $81.27 \%$ for chemical oxygen demand (COD).
\end{abstract}

KEYWORDS: Biogas, Renewable energy, Biochemical Methane Potential, Food Waste. 


\section{INTRODUÇÃO}

Os resíduos alimentares, componente majoritário no RSU brasileiro, compõem-se basicamente de cereais, carnes, massas, embutidos, ovos, frutos e verduras. São gerados em grandes quantidades, principalmente, nos estabelecimentos do segmento de alimentação, tais como restaurantes comerciais e coletivos, churrascarias, pizzarias, lanchonetes, bares bem como nos domicílios da população. Sua composição varia de acordo com os hábitos alimentares locais.

Tal desperdício é influenciado principalmente pela falta de planejamento do número de refeições, tipicidade do alimento, modo de preparo, ausência de indicadores de qualidade, compras feitas sem critérios, entre outros (ZANDONADI \& MAURICIO, 2012). Além disso, a geração de resíduo alimentar é inerente ao crescimento populacional, pois está ligada a todas as etapas da cadeia alimentar: assim, quanto maior a demanda por alimentos maior será a geração de resíduos alimentares (ZHANG et al., 2014).

A digestão anaeróbia de resíduos alimentares é um processo bastante complexo, uma vez que deve, simultaneamente, digerir carboidratos, proteínas e gorduras. O processo é influenciado diretamente por diversos parâmetros chave, como temperatura, $\mathrm{pH}$, concentração de ácidos graxos voláteis (AGV), de amônia, de nutrientes, entre outros. É extremamente importante manter tais parâmetros chave em níveis apropriados por um longo tempo de operação para que o processo seja eficiente com uma elevada redução nos contaminantes orgânicos e produção de biogás (CHERNICHARO, 2007; APPELS et al., 2011; ZHANG et al., 2014; WOON \& LO, 2016).

Na prática, a produção diária de biogás depende da quantidade de sólidos voláteis (SV) na carga de alimentação do biodigestor, já que os sólidos voláteis representam parte dos sólidos totais suscetíveis a serem biodegradados e convertidos em biogás. Portanto, o método mais utilizado para estimativas de geração de biogás é com base no teor de sólidos voláteis, permitindo assim verificar a viabilidade de produção de biogás a partir de determinado substrato. A Tabela 1 apresenta o potencial metanogênico para diferentes substratos.

Verifica-se na Tabela 1, que os resíduos alimentares possuem um bom potencial para a produção de biogás, apresentando valores de produção específica de metano acima da maioria dos substratos. Essa estimativa pode ser feita mediante estudos experimentais, realizada em reatores de bancada (escala de laboratório), como o ensaio Biochemical Methane Potential (BMP), que permite biodegradar o substrato e paralelamente mensurar a produção específica de metano por unidade de carga orgânica (DQO ou Sólidos Voláteis, principalmente).

Tabela 1. Potencial metanogênico de diferentes substratos orgânicos

\begin{tabular}{|c|c|c|}
\hline Resíduos & $\begin{array}{l}\text { Potencial metanogênico } \\
\left(\mathrm{m}^{3} \mathrm{CH}_{4 .} \mathrm{kgSV}^{-1} \text { b.s }\right)\end{array}$ & Fonte \\
\hline Frutas & 0,180 a 0,732 & \multirow{2}{*}{ Gunaseelan (2004) } \\
\hline Vegetais & 0,190 a 0,400 & \\
\hline Alimentares & 0,525 & Lissens et al. (2004) \\
\hline Alimentares & 0,479 & Zhang et al. (2011) \\
\hline Alimentares & 0,410 & Zhang et al. (2013) \\
\hline Peixe & 0,441 a 0,482 & \multirow{3}{*}{ Kafle et al. (2013) } \\
\hline Cervejaria & 0,316 & \\
\hline Pão & 0,306 & \\
\hline Esterco de Suíno & 0,568 & Amaral et al. (2016) \\
\hline $\begin{array}{l}\text { Esterco de Bovino } \\
\text { Leiteiro }\end{array}$ & 0,204 & \multirow{5}{*}{ Kafle \& Chen (2016) } \\
\hline Esterco de Cavalo & 0,155 & \\
\hline Esterco de Bode & 0,159 & \\
\hline Esterco de Frango & 0,259 & \\
\hline Esterco de Suíno & 0,323 & \\
\hline
\end{tabular}

O Ensaio BMP apesar de ainda não ser internacionalmente normatizado, é um método analítico de referência quando o intuito é obter maiores detalhes sobre a transformação de materiais orgânicos em metano (MACIEL, 2009). O processo de digestão anaeróbia é realizado sob condições ótimas de degradação, podendo ser considerado um processo de digestão anaeróbia acelerado.

$\mathrm{O}$ ambiente interno dos reatores BMP é mantido em anaerobiose estrita, por meio da remoção do oxigênio atmosférico com a injeção de N2 ou outro gás inerte no interior dos frascos reatores (OWEN et al., 1979). Logo, os reatores permanecem incubados em temperatura constante por um tempo de retenção hidráulica (TRH) mínimo de 30 dias para substratos simples e de 120 dias para substratos lignocelulósicos ou recalcitrantes, embora a norma ASTM E2170-01 recomende um TRH de 51 dias ou até que a produção de gás assuma estabilidade (Melo, 2010).

Por exemplo, nos ensaios BMP realizados por Gunaseelan (2004), foram utilizados resíduos de frutas e vegetais como substrato obtendo-se curvas de geração de metano que representam mais de $90 \%$ do total de metano gerado em um período de 30 a 40 dias. Ou seja, o TRH pode variar em função das características de cada experimento. O ensaio por ser realizado em diferentes temperaturas: 10 a $20^{\circ} \mathrm{C}$ (psicrofílico), 20 a $37^{\circ} \mathrm{C}$ (mesofilico) e de 37 a $70^{\circ} \mathrm{C}$ 
(termofilico).

A relação inoculo:substrato a ser utilizado depende dos objetivos da pesquisa, sendo calculada a partir do teor de sólidos voláteis das amostras, como $1: 1$ ou $1: 3$, por exemplo. O objetivo principal do ensaio é obter a produção específica de metano, usualmente, mensurando-se o volume de metano que foi possível obter a partir de uma quantidade (em peso) de sólidos voláteis reduzidos (SVr) do substrato (HAMILTON, 2012).

Sendo assim, objetivou-se neste trabalho verificar o potencial de geração de metano dos resíduos alimentares em reatores anaeróbios de bancada, por meio de ensaios de potencial bioquímico de metano.

\section{MATERIAL E MÉTODOS}

\section{Caracterização do inoculo e do substrato}

Os resíduos alimentares foram fornecidos por um restaurante popular do município de Cascavel (PR), que serve em média 700 refeições por dia, constituídas principalmente de cereais, massas, frutos, verduras, embutidos e carnes.

Os resíduos alimentares foram segregados (retirada de ossos e caroços) e processados em um liquidificador operado em rotações de 2000 e 22000 rpm, para reduzir o tamanho das partículas. Angelidaki et al. (2009) apontam que o tamanho das partículas é um parâmetro importante na taxa de produção de biogás, em virtude da redução da granulometria da amostra contribuir para uma maior reatividade da amostra e acelerar o tempo de degradação, fundamentais para estudos em escala laboratorial, como foi o caso desse experimento. Visando a homogeneidade da amostra de resíduos, os resíduos foram triturados, possibilitando assim aumentar a área superficial das partículas e promover maiores produções de biogás.

Logo, foram armazenados em garrafas PET de $2 \mathrm{~L}$ e mantidos a $-18^{\circ} \mathrm{C}$ de modo a preservar as características inalteradas até o dia dos ensaios. $\mathrm{O}$ inoculo foi obtido de um reator anaeróbio protótipo de mistura completa operando em regime de alimentação semicontínuo a digestão mesofílica $\left(30^{\circ} \mathrm{C}\right)$ de resíduos alimentares, instalado nas dependências da Universidade Estadual do Oeste do Paraná - Unioeste, campus Cascavel (PR).

\section{Análises físico-químicas e microbiológicas}

Foram realizadas amostragens dos resíduos antes e depois da incubação, devido ao processo ser em batelada. As análises $(\mathrm{pH}$, sólidos totais e voláteis, carbono orgânico

total - COT, nitrogênio total khendjal - NTK e demanda química de oxigênio - DQO) foram realizadas conforme as normas estabelecidas no American Public Health Association - APHA (2005).

\section{Ensaio BMP}

Para o experimento BMP, utilizaram-se reatores de bancada próprios à verificação do potencial de geração de biogás. Cada reator consistiu de um frasco de borossilicato com volume de $250 \mathrm{~mL}$, com tampas de polipropileno adaptadas com dois registros, um para mensurar a produção de biogás e o outro para a expurga e coleta do biogás gerado durante o processo de digestão anaeróbia, conforme metodologia descrita em Alves (2008). Para cada reator, em um dos registros foi acoplado um manômetro para medição da pressão interna, com leitura máxima de pressão igual a 2,5 kgf. $\mathrm{cm}^{-2}$ e escala de 0,10 kgf.cm ${ }^{-2}$, conforme apresentado na Figura 1.

(A)

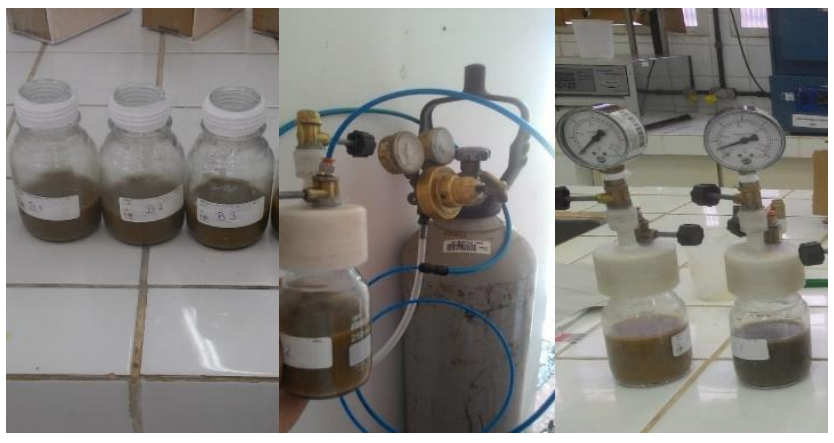

Figura 1. A) alimentação dos frascos reatores com suas respectivas amostras; $B$ ) recirculação de $\mathrm{N}_{2}$ no interior dos frascos reatores; e C) acoplamento do manômetro nos reatores para medição das pressões internas dos frascos.

Foram realizados 2 tratamentos: o tratamento $A$ (controle) constituiu-se apenas do inoculo; já o tratamento $B$ constituiu de uma mistura de inoculo e substrato, ambos trabalhados em triplicata, conforme sugerido por Angelidaki et al. (2009), para que possuam significância estatística. O esquema de alimentação dos reatores está apresentado na Tabela 2.

Após cada frasco reator receber a respectiva amostra de substrato e inoculo, as tampas foram hermeticamente fixadas nos vidros e uma corrente de gás nitrogênio $\left(\mathrm{N}_{2}\right)$ foi recirculada no headspace de cada frasco reator por cerca de quatro minutos, de modo a garantir a anaerobiose do meio. 
Tabela 2. Esquema de alimentação dos reatores batelada

\begin{tabular}{ccccc}
\hline Reatores & $\begin{array}{c}\text { Volume } \\
\text { Substrato }\end{array}$ & $\begin{array}{c}\text { Volume } \\
\text { Inoculo }\end{array}$ & Proporção & $\begin{array}{c}\text { Sólidos } \\
\text { Voláteis }\end{array}$ \\
\cline { 2 - 4 } & $m L$ & $\begin{array}{c}g S V_{\text {inoculo }} \\
g S V_{\text {substrato }}\end{array}$ & $g / L$ & \\
\hline $\begin{array}{c}\text { Tratamento } \\
\text { A }\end{array}$ & 0 & 100 & $1: 0$ & 11,62 \\
$\begin{array}{c}\text { Tratamento } \\
\text { B }\end{array}$ & 9 & 100 & $1: 1$ & 14,05 \\
$\begin{array}{c}\text { Inoculo } \\
\text { Substrato }\end{array}$ & - & - & - & 11,62 \\
\hline
\end{tabular}

O inoculo foi coletado no mesmo dia da incubação de modo a garantir a mínima atividade metanogênica. Optouse por utilizar o inoculo do reator protótipo uma vez que este tratava um substrato da mesma natureza, permitindo assim que a fase de aclimatação seja mais ágil, além de proporcionar melhores condições para o desenvolvimento microbiano. No entanto, ainda há muitas controvérsias sobre o melhor inoculo para determinado substrato, bem como a proporção ótima entre eles (AMARAL et al., 2008; SILVA, 2014).

Para o tratamento $B$, foi estipulada a proporção de 1:1 de resíduo:inoculo para realizar a interação dos resíduos alimentares com os microrganismos, de modo a estudar a taxa de degradação. De forma geral, a proporção adequada de resíduo:inoculo deve ser uma quantidade de inoculo ligeiramente maior que a de substrato (SILVA, 2014). Todos os reatores foram diariamente agitados manualmente por cerca de 4 minutos de modo a garantir um maior contato dos microrganismos com o substrato (ANGELIDAKI et al., 2009).

A partir disso, os reatores foram incubados em estufa microbiológica, permanecendo sob temperatura constante de $32 \pm 2{ }^{\circ} \mathrm{C}$, pelo tempo de retenção hidráulica (TRH) de 30 dias. Para os cálculos de volume de biogás gerado, foram monitoradas e anotadas diariamente as seguintes variáveis: a) Pressão interna dos reatores BMP, em kgf.cm ${ }^{-2}$; b) Temperatura do sistema na estufa, que foi constante e igual a $32 \pm 2{ }^{\circ} \mathrm{C}$; c) Dados de pressão atmosférica local, obtida através do site do Instituto Nacional de Meteorologia - INMET, de uma estação meteorológica localizada nas proximidades da UNIOESTE, campus Cascavel (PR).

Com esses dados, a pressão interna dos frascos foi convertida em termos de volume de biogás gerado e os valores de volume foram corrigidos às Condições Normais de Temperatura e Pressão - CNTP (MACIEL \& JUCÁ, 2011). Para as análises dos teores de metano $(\mathrm{CH} 4)$ e dióxido de carbono (CO2) do biogás gerado nos reatores de bancada, foi realizada a coleta do biogás no décimo dia do experimento, devido apresentar maior estabilidade à produção de biogás, sendo armazenado em ampolas gasométricas de $37 \mathrm{~mL}$, desenvolvidas pela empresa Construmaq São Carlos.

As alíquotas do gás foram coletadas em seringa com dispositivo de $\operatorname{trava}\left(\operatorname{Sigma}^{\circledR}\right)$ diretamente na sonda das ampolas gasométricas, de modo a evitar diluição das amostras com ar atmosférico. Os constituintes do biogás (dióxido de carbono e metano) foram determinados por cromatografia gasosa em sistema Shimadzu ${ }^{\circledR} 2010$ equipado com coluna capilar Carboxen ${ }^{\circledR} 1010$ plot (30 m x $0,53 \mathrm{~mm} \times 0,30 \mu \mathrm{m})$. Como gás de arraste foi utilizado argônio com vazão de ar de make-up de $8 \mathrm{~mL}$. $\mathrm{min}^{-1}$. Foram injetados $500 \mu \mathrm{L}$ de amostra e a temperatura do injetor foi ajustada para $200^{\circ} \mathrm{C}$. A detecção foi realizada em detector de condutividade térmica $(T C D)$ à temperatura de $230^{\circ} \mathrm{C}$. $\mathrm{O}$ forno foi programado para operar à temperatura inicial de $130^{\circ} \mathrm{C}$, sendo aquecido a $135^{\circ} \mathrm{C}$ à uma taxa de $46^{\circ} \mathrm{C} \cdot \mathrm{min}^{-1}$ durante 6 minutos.

\section{RESULTADOS E DISCUSSÃO}

As características do resíduo alimentar utilizado no experimento estão apresentadas na Tabela 3, juntamente com os dados obtidos por diferentes autores que também utilizaram resíduo alimentar como substrato para a produção de biogás. Todos os dados foram validados estatisticamente, apresentando coeficiente de variação abaixo de $0,5 \%$.

Tabela 3. Caracterização comparativa do resíduo alimentar

\begin{tabular}{ccccc}
\hline $\begin{array}{c}\text { Compo } \\
\text { nente }\end{array}$ & $\begin{array}{c}\text { Zhang et al. } \\
\text { (2007) }\end{array}$ & $\begin{array}{c}\text { Zhang et al. } \\
\text { (2011) }\end{array}$ & $\begin{array}{c}\text { Zhang et al. } \\
\text { (2013) }\end{array}$ & $\begin{array}{c}\text { Presente } \\
\text { estudo }\end{array}$ \\
\hline $\mathrm{pH}$ & $\mathrm{NC}$ & 6,5 & 4,2 & 5,98 \\
$\mathrm{ST}$ & $30,9 \%$ & $18,1 \%$ & $23,1 \%$ & $15,28 \%$ \\
$\mathrm{SV}$ & $26,35 \%$ & $17,1 \%$ & $21,0 \%$ & $13,02 \%$ \\
\hline $\mathrm{SV} / \mathrm{ST}$ & $85,30 \%$ & $94 \%$ & $100 \%$ & $85,21 \%$ \\
$\mathrm{C} / \mathrm{N}$ & 14,8 & 13,2 & 24,5 & 18,81 \\
\hline $\mathrm{C}$ total & $46,78 \%$ & $46,67 \%$ & $\mathrm{NC}$ & $44,4 \%$ \\
\hline $\mathrm{N}$ total & $3,16 \%$ & $3,54 \%$ & $\mathrm{NC}$ & $2,36 \%$ \\
\hline NC = Nada consta. & & &
\end{tabular}

Segundo Zhang et al. (2007), não existem variações significativas entre o efluente e afluente do processo de digestão anaeróbia quanto à concentração de nutrientes. De fato, os microrganismos consomem nutrientes em seus respectivos metabolismos, ainda assim, os micro e macro nutrientes permaneceram em níveis bastante semelhantes. Neste estudo, obteve-se um $\mathrm{pH}$ de 5,98 para os resíduos alimentares, valores dentro dos limites encontrados na literatura, assim como Zhang et al. (2013) 
encontraram o valor de 4,2 para os resíduos alimentares, valores significativamente ácidos que podem inibir a atividade dos microrganismos.

Quanto a fração orgânica dos resíduos alimentares, evidenciada pela concentração de sólidos voláteis, obtevese o percentual de $85,21 \%$, valor próximo aos encontrados por Zhang et al. (2007) e Zhang et al. (2011), que encontraram 85,30 e $94 \%$, respectivamente. Isso evidencia, portanto, que há presença de materiais passíveis de serem convertidos em metano.

A relação $\mathrm{C} / \mathrm{N}$ obtida no valor de 18,81 que é ligeiramente próximo ao limite inferior desejado à digestão anaeróbia, dado que a relação $\mathrm{C} / \mathrm{N}$ é referente à capacidade de digestão, onde uma relação adequada para o desenvolvimento dos microrganismos estaria contida na faixa de 20 a 30 (VERNA, 2002). Ainda assim, nota-se que o valor obtido neste estudo está próximo aos encontrados na literatura para resíduos alimentares. Isso se deve às concentrações de carbono e nitrogênio, que foram bastante similares às encontradas por Zhang et al. (2007) e Zhang et al. (2011).

\section{Potencial bioquímico de metano}

A determinação do potencial bioquímico de produção de metano dos resíduos alimentares, que se refere ao rendimento na produção de metano, foi avaliada a partir da construção de gráficos de taxa de geração e de volume acumulado ao longo do período de incubação das amostras. Todos os volumes de metano provenientes dos reatores batelada foram corrigidos para as CNTP. As Figuras 2a e 2b, apresentam, respectivamente, a taxa de geração e o volume acumulado de biogás nos 2 tratamentos avaliados.

Os resultados dispostos nas Figuras $2 a$ e $2 b$ representam as médias e desvios dos tratamentos $A$ e $B$, que apresentaram coeficientes de variação (CV) de 0,28 e 1,79 , respectivamente. É possível verificar nas Figuras $2 a$ e $2 \mathrm{~b}$ a velocidade de degradação dos resíduos alimentares, bem como a estabilidade da produção de biogás próximo ao $25^{\circ}$ dia, que conforme Melo (2010) pode ser utilizado como indicador para a finalização do ensaio de BMP. A queda na produção de biogás no $25^{\circ}$ dia de operação dos reatores BMP também foi observada por Silva (2015), que avaliou a biodegradabilidade de resíduos lácteos e obteve a maior geração de biogás no $15^{\circ}$ dia de operação dos reatores, evidenciando que o ensaio BMP conseguiu gerar resultados consistentes em até 30 dias.
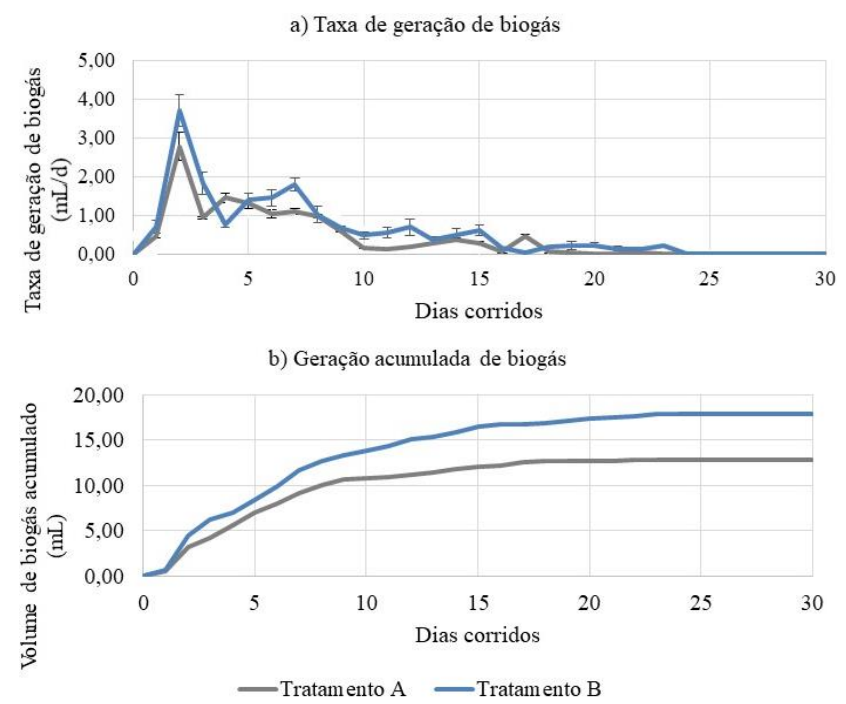

Figura 2. Geração de biogás dos resíduos alimentares: a) taxa de geração; e b) geração acumulada.

Nota-se na Figura 2a um pico na produção de biogás já nos primeiros dias do ensaio. Isso se deve às condições anaeróbias no início do experimento, realizada por meio da recirculação de $\mathrm{N} 2$ no interior dos frascos reatores que tornou o ambiente favorável ao desenvolvimento dos microrganismos anaeróbios e propício à atividade das metanogênicas (FIRMO, 2013). Pode-se justificar tais picos também devido à presença de substâncias solúveis facilmente biodegradáveis e ao elevado volume de inoculo, que permitiram uma hidrolise mais rápida, consequentemente, tornando o substrato rapidamente disponível às metanogênicas, que por sua vez, o converteram em metano (PARAWIRA et al., 2004; FERREIRA, 2013; SILVA, 2014).

O tratamento $\mathrm{B}$ (resíduo alimentar + inoculo) continha aproximadamente $20 \%$ a mais em concentração de sólidos voláteis do que o tratamento $\mathrm{A}$ (inoculo puro), conforme apresentado na Tabela 2; ainda assim, o pico de geração inicial de ambos os tratamentos foi bastante similar, denotando que não ocorreram inibições ou adversidades com o desenvolvimento dos microrganismos no sistema. Ou seja, pode-se considerar como um indicativo de que o inoculo conseguiu aclimatizar-se nos reatores e, sobretudo, consumir o substrato disponível (SILVA, 2014).

Quanto à produção de metano, o tratamento $B$ apresentou uma média 19,6\% maior que a produção do tratamento A, conforme consta na Tabela 4. Isso ocorreu devido à maior disponibilidade de material orgânico e às interações do inoculo com o substrato, pois onde há maior concentração de matéria orgânica remanescente no meio, mais rápido se processa a taxa de biodegradação e, portanto, proporcionando uma maior produção de biogás 
(VON SPERLING, 1996).

Os reatores, em geral, apresentaram resultados bastante semelhantes aos encontrados na literatura, com picos de geração logo no início do experimento e, ao longo do ensaio, as curvas começam a apresentar tendência à estabilidade na produção de metano. Assim como nos ensaios realizados por Alves (2008) operando reatores BMP com resíduos sólidos urbanos (RSU) de diferentes idades, que obteve a maior produção de biogás até o 5ำ dia em todos os ensaios.

Firmo (2013) também apresentou resultados bastante semelhantes ao biodegradar resíduos alimentares em reatores $\mathrm{BMP}$, identificando as maiores taxas de geração de biogás até o 10으 dia de ensaio. Von Sperling (1996) explica que, conforme se reduz a quantidade de matéria orgânica no reator, as taxas de degradação do resíduo e de geração de metano se tornam menores.

Em média, os tratamentos A e B apresentaram uma concentração de metano no biogás de $68,74 \%$ e $57,48 \%$, respectivamente. Os valores estão contidos na faixa desejável, visto que, conforme os dados encontrados na literatura, os teores de metano provenientes da digestão anaeróbia de resíduos alimentares variam entre 50 a $80 \%$, e em casos particulares a partir de 30\% (JUCÁ et al., 2005; ALVES, 2008).

Pode-se justificar o maior teor de metano para o tratamento A por se tratar de inoculo puro, proveniente de reator já em atividade que continha uma comunidade de metanogências já estabelecida; já quanto ao teor de metano do tratamento $B(57,48 \%)$, justifica-se que ocorreu uma maior geração de dióxido de carbono e outros gases $\left(\mathrm{NH}_{3}, \mathrm{H}_{2}, \mathrm{CO}, \mathrm{H}_{2} \mathrm{~S}\right.$ entre outros) na fase fermentativa da digestão anaeróbia, o qual aumentou consideravelmente o volume de biogás, consequentemente, diluindo a concentração de metano (ZHANG et al., 2014).

Silva (2014) relata que ao biodigerir resíduos alimentares unicamente, sem o auxílio de um inoculo, muitas vezes ocorre a produção de biogás, mas com teores de metano muito baixos e, algumas vezes, até nulo. A Tabela 4 apresenta os principais parâmetros de resposta do ensaio BMP.

$\mathrm{O} \mathrm{pH}$ para ambos os tratamentos apresentou valores dentro da faixa desejável no afluente, como apresentado por Bidone \& Pivonelli (1999), que apontam que os microrganismos apresentam melhor crescimento em $\mathrm{pH}$ próximo da neutralidade; por outro lado, valores fora dos limites de 6,3 e 7,8 podem inibir o crescimento de alguns microrganismos.

$\mathrm{O}$ inoculo (tratamento A) apresentou o $\mathrm{pH}$ de 7,84 e, portanto, dentro da faixa de neutralidade desejável à digestão anaeróbia; ainda assim, não foram constatadas inibições na atividade microbiana, evidenciado pela produção de metano em todas as réplicas dos reatores controle. No entanto, após os 30 dias de biodigestão, os efluentes dos tratamentos $A$ e $B$, apresentaram valores significativamente acima do limite desejável, 8,2 e 8,3, respectivamente.

Tabela 4. Caracterizações dos principais parâmetros do ensaio BMP

\begin{tabular}{|c|c|c|c|c|c|}
\hline \multirow[t]{2}{*}{ Parâmetro } & \multirow[t]{2}{*}{ Unidade } & \multicolumn{2}{|c|}{ Tratamento A } & \multicolumn{2}{|c|}{ Tratamento B } \\
\hline & & Entrada & Saída & Entrada & Saída \\
\hline $\mathrm{pH}$ & & 7,84 & 8,2 & 7,73 & 8,26 \\
\hline $\begin{array}{c}\text { Sólidos } \\
\text { totais }\end{array}$ & g. $\mathrm{L}^{-1}$ & 18,57 & 17,92 & 24,04 & 17,69 \\
\hline $\begin{array}{l}\text { Sólido } \\
\text { voláteis }\end{array}$ & g. $\mathrm{L}^{-1}$ & 11,62 & 10,96 & 14,05 & 10,73 \\
\hline SV/ST & $\%$ & \multicolumn{2}{|c|}{62,57} & \multicolumn{2}{|c|}{58,44} \\
\hline DQO & $\mathrm{g} \mathrm{O}_{2} \cdot \mathrm{L}^{-1}$ & 99,465 & 18,911 & 101,015 & 18,550 \\
\hline $\mathrm{BMP}_{\text {biogas }}$ & $\begin{array}{c}\mathrm{Nm}^{3} \cdot \mathrm{kg} \mathrm{DQOr}^{-1} \\
\mathrm{Nm}^{3} \cdot \mathrm{kgSVr}^{-1}\end{array}$ & \multicolumn{2}{|c|}{$\begin{array}{c}0,1596 \\
0,419\end{array}$} & \multicolumn{2}{|c|}{0,2176} \\
\hline $\mathrm{BMP}_{\text {metano }}$ & $\begin{array}{c}\mathrm{Nm}^{3} \cdot \mathrm{kg} \mathrm{DQOr}^{-1} \\
\mathrm{Nm}^{3} \cdot \mathrm{kgSVr}^{-1}\end{array}$ & \multicolumn{2}{|c|}{0,1029} & $\begin{array}{c}0,1 \\
0,\end{array}$ & \\
\hline $\begin{array}{l}\text { Metano/ } \\
\text { Biogás }\end{array}$ & $\%$ & \multicolumn{2}{|c|}{$68,74 \pm 1,36$} & \multicolumn{2}{|c|}{$57,48 \pm 0,62$} \\
\hline Reduções & $\begin{array}{c}\% \text { DQO } \\
\% \text { SV }\end{array}$ & \multicolumn{2}{|c|}{80,98} & \multicolumn{2}{|c|}{81,63} \\
\hline
\end{tabular}

Crovador (2014) explica que muitas vezes, o aumento do $\mathrm{pH}$ ao final do processo anaeróbio pode ser devido à armazenagem do biogás no headspace do reator, que promove reações do solúvel dióxido de carbono com a solução aquosa do reator. De acordo com a Lei de Henry, que governa a solubilidade dos gases, juntamente com a Lei de Dalton, $\mathrm{O} \mathrm{CO}_{2}$ permanece em equilíbrio variando entre as formas gasosa e aquosa. Com a produção de $\mathrm{CO}_{2}$ na biodegradação e a dinâmica da lei de Henry, esse gás do headspace solubiliza-se na fase líquida do biodigestor (SCHIRMER et al., 2014), onde reage com água formando bicarbonatos, que implicam no aumento da alcalinidade e do $\mathrm{pH}$ (VON SPERLING, 2005).

Quanto ao teor de matéria orgânica, evidenciado pelos sólidos voláteis, verifica-se que o tratamento $A$ apresenta uma concentração moderada, na faixa de $11,62 \mathrm{~g}$. $\mathrm{L}^{-1}$, pois sua matéria orgânica já havia sido, em grande parte, mineralizada no reator que a originou. Fator este que também resultou na baixa concentração de voláteis do tratamento $B\left(14,05\right.$ g. $\left.\mathrm{L}^{-1}\right)$, pois mesmo com a adição do substrato, na proporção de 1:1, a concentração de voláteis elevou-se muito pouco.

Deve-se levar em conta que o volume de substrato adicionado foi extremamente baixo, devido à relação de 1:1 em gSTV substrato:gSTV $_{\text {inoculo }}$ resultar em um volume de 9 $\mathrm{mL}$ de substrato adicionado no tratamento B. Ainda assim, a proporção de voláteis obtida de $62,57 \%$ e 58,44\%, para 
os tratamentos A e B, respectivamente, estão dentro da faixa considerada ótima para ensaios de biodegradação, devido aos benefícios promovidos à ação microbiana (ALVES, 2008)

Já no que diz respeito à DQO, nota-se que os valores encontrados são coerentes com a literatura, onde os tratamentos A e B apresentaram uma concentração de 99,45 a 101,01 g O2. $\mathrm{L}^{-1}$, respectivamente. Santos (2015), ao biodigerir resíduos alimentares em um reator piloto, apontou uma DQO de 74,5 $\mathrm{g} \mathrm{O}_{2} . \mathrm{L}^{-1}$ para afluente da amostra contendo resíduos alimentares e inoculo (dejeto bovino). Tais valores são ligeiramente superiores aos encontrado por Ratanatamskul et al. (2014), que obteve na caracterização dos resíduos alimentares o valor de 232,795 $\mathrm{mg} \mathrm{O} \mathrm{O}_{2} \mathrm{~L}^{-1}$. Crovador (2014), ao realizar ensaios BMP com a fração orgânica de RSU, obteve uma DQO para o afluente das amostras de $34,46 \mathrm{~g} \mathrm{O} 2 \cdot \mathrm{L}^{-1}$.

Foi possível reduzir em $5,61 \%$ a concentração de sólidos voláteis do tratamento $A$ e $23,58 \%$ do tratamento $B$. Essa redução baixa se deve ao pequeno tempo de retenção hidráulica, de 30 dias, que não foi suficiente para mineralizar os materiais orgânicos de mais difícil degradação, tais como os lignocelulósicos presentes nos resíduos alimentares (CROVADOR, 2014). Nota-se ainda que nos efluentes de ambos os tratamentos, a concentração de sólidos voláteis é bastante semelhante (por volta de 10 a 11\%), sinalizando que de fato existem materiais recalcitrantes de difícil degradação. No entanto, Decottignies et al. (2005) aponta que um resíduo pode ser considerado estabilizado quando apresentar faixas de sólidos voláteis entre 10 e 17,4\%; Kelly (2002) relata que os resíduos podem ser considerados estabilizados quando as concentrações de sólidos voláteis forem menores que $20 \%$.

Pode-se dizer que houve a digestão do substrato, indicada pela redução da DQO, onde foi possível reduzir em $80,98 \%$ no tratamento A e $81,63 \%$ no tratamento B. Considera-se uma remoção bastante significativa devido ao curto tempo de retenção hidráulica (TRH) de 30 dias, mesmo assim o processo converteu uma parte da matéria orgânica sólida para biogás. Santos (2015), operando a digestão anaeróbia em regime psicrofílico de resíduos alimentares em um reator em escala piloto, conseguiu obter uma remoção de $84 \%$ na DQO e $94 \%$ para SV.

No que diz respeito ao teor de metano na produção de biogás da fermentação dos resíduos alimentares, utilizouse a relação de biogás e metano produzido por unidade de sólido volátil reduzido ou consumido. O tratamento $A$ apresentou o valor de 0,419 $\mathrm{Nm}_{3} . \mathrm{kgSVr}^{-1}$ e $0,241 \mathrm{Nm}_{3} \mathrm{CH} 4 . \mathrm{kgSVr}^{-1}$, e para o tratamento $\mathrm{B}$ foi obtido o valor de 0,541 $\mathrm{Nm}_{3} . \mathrm{kgSVr}^{-1}$ e 0,311 $\mathrm{Nm}_{3} \mathrm{CH}_{4} . \mathrm{kgSVr}^{-1}$, valores próximos aos encontrados na literatura.

Zhang et al. (2013) obtiveram, em seu trabalho, o rendimento na produção de biogás dos resíduos alimentares em $0,621 \quad \mathrm{Nm}_{3} . \mathrm{kgSVr}^{-1} \quad \mathrm{e}$ 0,410 $\mathrm{Nm}_{3} \mathrm{CH} 4 . \mathrm{kgSVr}^{-1}$. Haider et al. (2015) realizaram a codigestão dos resíduos alimentares com casca de arroz e alcançaram uma produção específica de biogás de 0,557 Nm3.kgSVr ${ }^{-1}$. Cho, Park e Chang (1995) alcançaram com ensaios BMP utilizando resíduos alimentares o valor de 0,472 $\mathrm{Nm}_{3} \mathrm{CH} 4 . \mathrm{kgSVr}^{-1}$, faixa bastante semelhante ao obtido por Hansen et al. (2004), que atingiu o valor de $0,495 \mathrm{Nm}_{3} \mathrm{CH}_{4} . \mathrm{kgSV}^{-1}$.

Portanto, por mais que os resíduos alimentares apresentem características quanto a sua composição bastante distintas de região para região, ainda assim, constituem-se de uma fonte renovável interessante para produção de metano, uma vez que apresenta um excelente rendimento se comparado aos demais substratos que são comumente utilizados, apresentados na Tabela 1.

\section{CONCLUSÕES}

Os resíduos alimentares se mostraram substratos bastante promissores à produção de biogás por suas características biodegradáveis que foram verificadas nos processos de digestão anaeróbia. As caracterizações físicoquímicas dos resíduos alimentares apresentaram valores ideais para o processo de digestão anaeróbia, uma vez que foi possível realizar os ensaios de biodegradabilidade com o material in natura, sem a necessidade de inserção de soluções nutritivas. Ainda assim, é aconselhável a utilização de cosubstratos alternativos na mistura para longos períodos de operação. Os resíduos alimentares apresentaram, em média, teor de sólidos voláteis na faixa de $85,21 \%$ e a relação $\mathrm{C} / \mathrm{N}$ de 18,4 , quais conforme a literatura, são favoráveis ao processo de digestão anaeróbia.

O ensaio de Potencial Bioquímico de Metano (BMP) se mostrou como uma ferramenta eficiente para a verificação da biodegradabilidade dos resíduos alimentares, gerando resultados satisfatórios em curto espaço de tempo (30 dias), sendo possível obter um rendimento de metano na faixa de 0,311 $\mathrm{m}^{3} \mathrm{CH} 4 . \mathrm{kgSVr}^{-1}$ e alcançar reduções de matéria orgânica na ordem de 23,58 \% para os SV e de $81,63 \%$ para a DQO.

Conclui-se que os resíduos alimentares podem ser utilizados no processo de digestão anaeróbia, caracterizando-se como uma ferramenta fundamental para a gestão dos resíduos sólidos urbanos (RSU) no país, uma vez que reduz a carga contaminante dos resíduos e 
pode reduzir em aproximadamente $50 \%$ o volume de resíduos sólidos destinados para os aterros sanitários além de contribuir com a matriz energética nacional bem como para oxidar o metano à dióxido de carbono.

\section{REFERÊNCIAS}

ALVES, I. R. F. S. Análise experimental do potencial de geração de biogás em resíduos sólidos urbanos. 2008. 134 f. Dissertação (Mestre em Engenharia Civil) - Universidade Federal de Pernambuco, Recife, 2008.

AMARAL, A. C.; KUNZ, A.; STEINMETZ, R. L. R.; SCUSSIATO, L. A.; TÁPPARO, D. C.; GASPARETO, T. C. Influence of solid-liquid separation strategy on biogas yield from a stratified swine production system. Journal of Environmental Management, v. 168, p. 229-235, 2016.

AMARAL, M. C. S.; FERREIRA, C. F. A.; LANGE, L. C.; AQUINO, S. F. Avaliação da biodegradabilidade anaeróbia de lixiviados de aterros sanitários. Engenharia Sanitária e Ambiental, v. 13, n. 1, p. 38-45, 2008.

AMERICAN PUBLIC HEALTH ASSOCIATION - APHA. Standard methods for the examination of water and wastewater. 21. ed. Washington: American Public Health Association, American Water Works Association, Water Environmental Federation, 2005.

ANGELIDAKI, I.; ALVES, M.; BOLZONELLA, D.; BORZACCONI, L.; CAMPOS, J. L.; GUWY, A. J.; KALYUZHNYI, S.; JENICEK, P.; VAN LIER, J. B. Defining the biomethane potential (BMP) of solid organic wastes and energy crops: a proposed protocol for batch assays. Water Science \& Technology, v. 59. n. 5, p. 927-934, 2009.

APPELS, L.; ASSCHEB, A. V.; WILLEMSB, K.; DEGRÈVEA, J.; IMPEA, J. V.; DEWIL, R. Peracetic acid oxidation as an alternative pretreatment for the anaerobic digestion of waste activated sludge. Bioresource Technology, v. 102, n. 5, p. 4124-4130, 2011.

BIDONE, F. R. A.; POVINELLI, J. Conceitos básicos de resíduos sólidos. São Paulo: EESC/Universidade de São Paulo, 1999. 120 p.

CHERNICHARO, C. A. L. Reatores anaeróbios. Belo Horizonte: Departamento de Engenharia Sanitária e Ambiental, v. 5, n. 2, 2007. $380 \mathrm{p}$.

CHO, J. K.; PARK, S. C.; CHANG, H. N. Biochemical methane potential and solid state anaerobic digestion of korean food wastes. Bioresource Technology, v .52, n. 3, p. 245-253, 1995.

CROVADOR, M.I.C. Potencial de geração de biogás a partir da fração orgânica de resíduos sólidos urbanos. 2017. $119 \mathrm{f}$. Dissertação (Mestrado em Bioenergia) - Universidade Estadual do Centro Oeste, Irati, 2014.

DECOTTIGNIES, V.; GALTIER, L.; LEFEBVRE, X; VILLERIO, T. Comparison of analytical methods to determine the stability of municipal solid waste and related wastes. In: Proceedings Sardinia, Tenth International Waste Management and Landfill Symposium, 2005.
DEUBLEIN, D.; STEINHAUSER, A. Biogas from waste and renewable resources: an introduction. Weinheim: Wiley- $\mathrm{VCH}$ Verlag Gmbh \& Co. KGaA, 2008.

FERREIRA, L. M. S. Biodigestão anaeróbia de dejetos de bovinos leiteiros com e sem separação da fração sólida. 2013. $67 \mathrm{f}$. Dissertação (Mestre em Zootecnia) - Faculdade de Ciências Agrárias e Veterinárias - Universidade do Estado de São Paulo, Jaboticabal, 2013.

FIRMO, A. L. B. Estudo numérico e experimental da geração de biogás a partir da biodegradação de resíduos sólidos urbanos. 2013. 286 f. Tese (Doutorado em Engenharia Civil) - Universidade Federal de Pernambuco, Recife, 2013.

GUNASEELAN, V. N. Biochemical methane potential of fruits and vegetables solid waste feedstocks. Fuel and Energy Abstracts, v. 36, n. 5, p. 403-403, 2004.

HAIDER, M. R.; ZESHAN; YOUSAF, S.; MALIK, R. N.; VISVANATHAN, C. Effect of mixing ratio of food waste and hice husk co-digestion and substrate to inoculum ration on biogas production. Bioresource Technology, v. 190, p. 451-457, 2015.

HAMILTON, D. W. Anaerobic digestion of animal manures: methane production potential of wastes materials. Oklahoma State University: Division of Agricultural Sciences and Natural Resources: BAE-1762, 2012.

HANSEN, T. L.; SCHIMIDT, J. E.; ANGELIDAKI, I.; MARCA, E.; JANSEN J. I.; MOSBAEK, K.; CHRISTENSEN, T. H.; Method for determination of methane potential of solid organic waste. Waste Management, v. 24, n. 4, p. 393-400, 2004.

JUCÁ, J. F. T.; MACIEL, F. J.; MARIANO, M. O. H.; BRITO, A. R. Relatório técnico do estudo de aproveitamento energético do biogás no aterro da Muribeca. Recife: Universidade Federal de Pernambuco - Grupo de Resíduos Sólidos, 2005.

KAFLE, G. K.; CHEN, L. Comparison on batch anaerobic digestion of five different livestock manure and prediction of potential methane production (BMP) using different statistical models. Waste Management, v. 48, p. 492-502, 2016.

KAFLE, G. K.; KIM, S. H.; SUNG, K. I. Ensiling of fish industry waste for biogas production: A lab scale evaluation of biochemical methane potential (BMP) and kinetics. Bioresource Technology, v. 127, p. 326-336, 2013.

KELLY, R. J. Solid waste biodegradation enhancements and the evaluation of analytical methods used to predict waste stability. 2002. 66 f. Dissertação (Master of Science in Environmental Science and Engineering) - Faculty of Virginia Polytechnic Institute and State University, Blacksburg-Virginia, 2002.

LISSENS, G.; THOMSEN, A. B.; DE BAERE, L.; VERSTRAETE, W.; AHRING, B. K. Thermal wet oxidation improves anaerobic biodegradability of raw and digested biowaste. Environmental Science and Technology, v. 38, n. 12, p. 3418-3424, 2004.

MACIEL, F. J. Geração de biogás e energia em aterro experimental de resíduos sólidos urbanos. 2009. 333 f. Tese (Doutorado) - Universidade Federal de Pernambuco, Recife, 2009. 
MACIEL, F. J.; JUCÁ, J. F. T. Evaluation of landfill gas production and emissions in a MSW large-scale experimental cell in Brazil. Waste Management, v. 31, n. 5, p. 966-977, 2011.

MELO, E. S. R. L. Análise de biodegradabilidade dos materiais que compõem os resíduos sólidos urbanos através de ensaios BMP (Biochemical Methane Potential). 2010. 148 f. Dissertação (Mestre em Engenharia Civil) - Universidade Federal de Pernambuco, Recife, 2010.

OWEN, W. F.; STUCKEY, D. C.; HEALY, J. B.; YOUNG, L. Y. JR., MCCARTY, P. L. Bioassay for monitoring biochemical methane potential and anaerobic toxicity. Water Research. v. 13, p. 485492, 1979.

PARAWIRA, W.; MURTO, M.; ZVAUYA, R.; MATTIASSON, B. Anaerobic batch digestion of solid potato waste alone and in combination with sugar beet leaves. Renewable Energy, v.29, n. 11, p. 1811-1823, 2004.

RATANATAMSKUL, C.; ONNUM, G.; YAMAMOTO, K. A prototype single-stage anaerobic digester for co-digestion of food waste and sewage sludge from high-rise building for on-site biogas production. International Biodeterioration \& Biodegradation, v. 95, p. 176-180, 2014.

SANTOS, V. G. Tratamento de resíduos sólidos de refeições de restaurante e produção de biogás em reator anaeróbio em escala piloto. 2015. 100 f. Dissertação (Mestrado) - Fundação Universidade Regional de Blumenau, Blumenau, 2015.

SCHIRMER, W. N.; JUCÁ, J. F. T.; SCHULER, A. R. P.; HOLANDA, S.; JESUS, L. L. Methane production in anaerobic digestion of organic waste from Recife (Brazil) Landfill: 102 evaluation in refuse of different ages. Brazilian Journal of Chemical Engineering, v. 31, n. 2, p. 373-384, 2014.

SILVA, M. C. P. Avaliação de lodo anaeróbio e dejeto bovino como potencial inoculos para partida de digestores anaeróbios de resíduos alimentares. 2014. 115 f. Dissertação (Mestrado) Universidade Federal de Minas Gerais, Belo Horizonte, 2014.

TCHOBANOGLOUS, G.; THEISEN, H.; VIGIL, S. Integrated solid waste management: engineering principles and management issues. New York: Mcgraw-Hill, 1993. 978 p.

VERNA, S. Anaerobic digestion of biodegradable organics in municipal solid wastes. 2002. 50 f. Dissertação (Master in Earth Resources Engineering) - Columbia University, New York, 2002.

VON SPERLING, M. Princípios básicos do tratamento de esgotos. Belo Horizonte: Departamento de Engenharia Sanitária e Ambiental, Universidade Federal de Minas Gerais, 1996. 211 p.

VON SPERLING, M. Introdução à qualidade das águas e ao tratamento de esgotos. 3. ed. Belo Horizonte: Departamento de Engenharia Sanitária e Ambiental, Universidade Federal de Minas Gerais, 2005. 452 p.

WOON, K. S.; LO, I. M. C. A proposed framework of food waste collection and recycling for renewable biogas fuel production in Honk Kong. Waste Management, v. 47, p. 3-10, 2016. ingesta, de refeições consumidas por trabalhadores da construção civil no município de Cuiabá, MT. Revista Higiene Alimentar, v. 26, n. 206/207, p. 64-70, 2012.

ZHANG, C.; SU, H.; BAEYENS, J.; TAN, T. Reviewing the anaerobic digestion of food waste for biogas production. Renewable and Sustainable Energy Reviews, v. 38, p. 383-392, 2014.

ZHANG, C.; SU, H.; TAN, T. Batch and semi-continuous anaerobic digestion of food waste in a dual solid-liquid system. Bioresource Technology, v. 145, p. 10-13, 2013.

ZHANG, L.; LEEB, Y-W.; JAHNGA, D. Anaerobic co-digestion of food waste and piggery wastewater: Focusing on the role of trace elements. Bioresource Technology, v. 102, n. 8, p. 5048-5059, 2011.

ZHANG, R.; EL-MASHAD, H. M.; HARTMAN, K.; WANG, F.; LIU, G.; CHOATE, C.; GAMBLE, P. Characterization of food waste as feedstock for anaerobic digestion. Bioresource Technology, v. 98, p. 929-935, 2007. 